\title{
Entre Colonia y República: fiscalidad en Ecuador, Colombia y Venezuela, 1780-1845
}

\author{
I JOSÉ JOAQU ÍN PINTO BERNAL \\ Bogotá: Instituto Colombiano de Antropología e Historia \\ 2018 | ISBN 9789588852508 | 385 pp.
}

DOI: https://doi.org/I0.22380/20274688.1464

JOHAN SEBASTIÁN TORRES GÜIZA

Instituto de Investigaciones Dr. José María Luis Mora

https://orcid.org/0000-0002-0834-9296

ntre Colonia y República: fiscalidad en Ecuador, Colombia y Venezuela, I780-
I845 es el libro producto de la tesis homónima realizada por José Joaquín Pinto Bernal para obtener el grado de doctor en Historia en la Universidad Nacional de Colombia (sede Bogotá), sustentada en el 2014 bajo la dirección del Dr. Heraclio Bonilla. Se trata de una obra de historia comparada de largo aliento que supera el marco espacial de los Estados nacionales contemporáneos y presenta los cambios y las continuidades del aparato fiscal en Colombia, Ecuador y Venezuela entre I780 y I845, incorporando en su análisis la política, la guerra, la economía y el comercio como causas y consecuencias del devenir del sistema fiscal en los tres contextos.

Dividido en seis capítulos, Entre Colonia y República resulta un libro innovador, toda vez que entrelaza la evolución de las haciendas reales y las haciendas nacionales en un territorio que compartió durante siglos una matriz institucional común, elemento ausente en la historiografía hispanoamericana. En el primer capítulo, "Balance y perspectivas para una historia fiscal de Ecuador, Colombia y Venezuela entre 1780 y I845", el autor identifica las distintas 
tradiciones historiográficas que tratan la relación entre fisco y estructura política y económica, apuntalando que, hasta entonces, la producción historiográfica en los tres contextos se circunscribe al estudio de la fiscalidad en el ámbito nacional, configuración espacial inexistente para la época. Además, sitúa su obra dentro de la "vertiente integral" de los estudios históricos del fisco que entiende "al fisco como un escenario de integración, en el cual la explicación de sus transformaciones y permanencias depende de diversas variables provenientes del ámbito político y económico, donde el sistema fiscal ocupa un papel de síntoma y a la vez de causa de las características de cada ámbito" (74), y presenta su objetivo: describir y explicar la historia del sistema fiscal en su esfera formal y factual en Colombia, Ecuador y Venezuela entre 1780-I845, producto y a la vez condicionante del grado de consolidación del poder estatal, los objetivos de gobierno, las características de las actividades económicas y la estabilidad del orden social (78).

Los siguientes cinco capítulos dan cuenta de una periodización sustentada en los cambios de orden político entre 1780 y I845, siendo el binomio guerrafiscalidad el hilo conductor empleado por Pinto Bernal para analizar un periodo en el que una y otra vez el sistema fiscal es reconfigurado por cada gobierno que asume el poder. Los argumentos y la evidencia sobre las continuidades y las rupturas fiscales entre cada periodo están ordenados dentro de secciones por capítulo, en las cuales, primero, Pinto Bernal describe el régimen legal que orienta al fisco (estructura formal) con base en las ordenanzas, las leyes, los decretos y los reglamentos de la época; luego, describe la dinámica de recaudo y gasto en términos cuantitativos (estructura factual), con la reconstrucción de las series a partir de los libros mayores y sus sumarios, los estados generales y las diligencias anuales de corte y tanteo preparadas por los oficiales encargados del fisco; y, finalmente, explica cómo la política, la economía y el orden social determinaron y fueron determinados por el aparato fiscal, apoyado en los avances historiográficos sobre Colombia, Ecuador y Venezuela.

Como resultado, el segundo capítulo se refiere a "La Real Hacienda en el Virreinato de la Nueva Granada, la Audiencia de Quito y la Intendencia de Venezuela" entre 1780 y I809, periodo en el que la Corona emprende una reforma de centralización administrativa de la Real Hacienda, acompañada del aumento de la presión fiscal. En su análisis, por una parte, Pinto Bernal identifica una estructura de ingreso altamente dependiente de los impuestos indirectos al comercio y de los monopolios productivos, con buenos resultados en el periodo de paz de I783-I793 y una tendencia a la baja en el último decenio; 
por otra parte, identifica tesorerías cuya principal fuente de ingresos fueron los monopolios (Antioquia, Cartago, Honda, Citará, Mompox, Santa Marta y Santafé), el tributo indígena (Cuenca y Quito), las remisiones de otras cajas (Cartagena, Popayán y Panamá) y el impuesto al comercio (Guayaquil), y logra constatar que "los ingresos fiscales fluctúan con arreglo a las características de cada región y no corresponden de igual forma en el conjunto del Virreinato durante cada decenio" (134). Esta explicación es decisiva para entender tanto el sistema fiscal en su totalidad virreinal como en su particularidad regional, pues los estudios sobre las cajas reales neogranadinas se habían enfocado en investigaciones parciales de algunas cajas (Pinto y Díaz; Arévalo y Rodríguez; Pinto, "Fiscalidad e independencia en Santafé"; Pinto, "Fiscalidad e independencia en Panamá”; Rodríguez) o en la segmentación de estas por su ubicación geográfica, sin considerar las cajas de la Audiencia de Quito (Meisel).

El tercer capítulo analiza las transformaciones experimentadas por la estructura fiscal producto del inicio del proceso de independencia en el periodo de I8Io-I8I9, para lo cual detalla las formas de administración, la política fiscal y el comportamiento cuantitativo del tesoro público diseńado por los gobiernos independentistas y sus contrapartes realistas en medio de la guerra. Se trata de un periodo de crisis, manifiesto en la caída de los ingresos fiscales y un elevado gasto debido al conflicto armado, afrontado por los gobiernos de turno con la emisión de papel moneda, el recurso del crédito, la apropiación de rentas, el restablecimiento de gravámenes erogados, el secuestro de bienes y los empréstitos forzosos. Queda claro entonces que la guerra, el deterioro de las actividades económicas y el desorden político significaron un constante cambio en la política fiscal con arreglo al interés provincial y al desarrollo de la confrontación armada que, en todo caso, no implicó el restablecimiento del orden fiscal, político y económico anterior a I809.

El siguiente capítulo, que se ocupa de la "Fiscalidad en la República de Colombia, I819-I830", analiza el sistema fiscal con arreglo a un modelo centralista que intentó erigir a Bogotá como centro para la determinación y el manejo del aparato fiscal de la República de Colombia. Sin embargo, Pinto Bernal detalla cómo, a pesar del triunfo militar de I824 en la batalla de Ayacucho, el proyecto de centralización no pudo hacerse realidad, pues tuvo que ceder cada vez mayor autonomía a las regiones para el manejo de sus fondos, sobre todo con la creación de la Junta Superior de Hacienda de Caracas (I828) y las juntas de árbitros y juntas provisionales de distrito en Ecuador (I829). En materia fiscal, la República se mantuvo en medio del déficit, lo cual hizo necesario que 
se restituyeran los gravámenes eliminados y que se recurriera al crédito para cubrir las obligaciones financieras. En consecuencia, se invirtió solamente el $3 \%$ en el fomento de la producción del tabaco y en las mejoras de las casas de la moneda. Lo anterior lleva a Pinto Bernal a pensar que "guerra, déficit, deuda e inestabilidad política e institucional fueron la constante durante la Gran Colombia. Estos factores sumados al reconocimiento de autonomía fiscal dieron como resultado la conformación de tres nuevos Estados en I830" (273), cuestión de la que se ocupa en el último capítulo.

En el acápite en mención, "Fiscalidad en tres nacientes repúblicas, I830I845", el autor constata la permanencia de un Estado débil en Colombia, Ecuador y Venezuela, sustentado en una economía de lento crecimiento y altamente vulnerable a las fluctuaciones del mercado externo. Así, expone cómo cada Estado intentó imponer una estructura administrativa de centralización del fisco, con una política conservadora en Colombia y Ecuador, mientras que en Venezuela se impuso un modelo reformista para el aparato fiscal. Este último modelo limitó la emergencia de movimientos de oposición afectados por la elección de una de las dos alternativas, proceso que terminó con el inicio de fases de transición hacia una mayor autonomía fiscal en 1845. Finalmente, en el apartado de conclusiones, Pinto Bernal presenta un balance general de los cambios y las continuidades del aparato fiscal en el espacio de estudio entre 1780 y 1845 y señala que dicho proceso estuvo condicionado y a la vez condicionó la estructura política y económica de las nuevas repúblicas.

En síntesis, Entre Colonia y República no se limita a la mera descripción institucional del fisco y a la reconstrucción de las series que dan cuenta del recaudo y el gasto de las instituciones políticas, en cambio, se preocupa por explicar la relación de mutua determinación que se entabla entre el fisco y el orden social, económico y político de Colombia, Ecuador y Venezuela entre 1780 y I845. Resulta siendo una obra de sumo interés tanto para los interesados en la historia fiscal comparada y el aparato fiscal del Estado y su desarrollo, pues invita a superar los marcos analíticos de los Estados nacionales contemporáneos y ahondar en los fenómenos de naturaleza fiscal desde una perspectiva más amplia que parta de matrices institucionales comunes, como para todo aquel interesado en comprender los fenómenos de la esfera política y económica del periodo que media entre el antiguo orden virreinal y la conformación de las nuevas repúblicas. De esta manera, con el libro de Pinto Bernal queda clara la íntima relación entre fiscalidad, política y economía. 
Por último, es necesario resaltar que el texto se acompaña de recurrentes cuadros y gráficas, lo cual le permite al lector verificar los cambios y las permanencias en la estructura formal y factual del fisco en cada una de las etapas y evaluar los resultados de las reformas administrativas en términos cuantitativos. Asimismo, fuera de las interpretaciones del autor con base en sus datos, Entre Colonia y República ofrece al lector un completo anexo estadístico disponible en la página web del editor, en el que Pinto Bernal transcribe los sumarios de cargo y data de las cajas reales de los tres contextos analizados, entre 1780 y I845 (Pinto, "Anexo"). Esto es positivo para la historiografía fiscal hispanoamericana porque se ofrece una transcripción y tabulación de fuentes cuantitativas que, de otra manera, solo se podrían consultar en el Archivo General de la Nación de Colombia, el Archivo Nacional del Ecuador y el David M. Rubenstein Rare Book \& Manuscript Library de la Universidad de Duke, lo que naturalmente ahorra costos de tiempo y dinero para los investigadores interesados en ese mismo corpus documental y, dadas las proporciones, complementa el imponente trabajo de reconstrucción de las series de cargo y data de las cajas reales llevado a cabo por Herbert Klein, John Jey TePaske, Álvaro Jara y Kendall W. Brown para distintas jurisdicciones del antiguo imperio español.

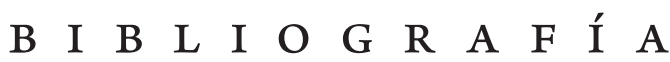

Arévalo Hernández, Decsi Astrid y Oscar Rodríguez Salazar. "La fiscalidad bajo un régimen de dominación colonial: el caso de la Caja Real de Cartagena, 1738-1802". Anuario Colombiano de Historia Social y de la Cultura, n. ${ }^{\circ}$ 35, 2008, pp. 19-64.

Klein, Herbert S. e Isabel Vericat. Las finanzas americanas del imperio español, I680-I800. Ciudad de México: Instituto de Investigaciones José María Luis Mora, I999.

Meisel Roca, Adolfo. Crecimiento, mestizaje y presión fiscal en el Virreinato de la Nueva Granada, I76I-I80o. Bogotá: Banco de la República, 2010.

Pinto Bernal, José Joaquín. “Anexo estadístico”. Entre Colonia y República. Fiscalidad en Ecuador, Colombia y Venezuela, I780-1845. Bogotá: ICANH, febrero de 2018, https:// www.icanh.gov.co/index.php?idcategoria $=15939$.

--.. "Fiscalidad e independencia en Panamá, I780-I845". Tiempo y Economía, vol. I, n. ${ }^{\circ}$ I, 2014 , pp. II-37. DOI: https://doi.org/I0.21789/24222704.943. 
---. "Fiscalidad e independencia en Santafé y Bogotá, 1780-1830". América Latina en la Historia Económica, vol. 22, n. ${ }^{\circ}$ 3, 2015 , pp. 7-43. DOI: https://doi.org/I0.18232/alhe.v22i3.649.

Pinto Bernal, José Joaquín y Carlos Alfonso Díaz Martínez. "Fiscalidad en Popayán, 1750-1821". Tiempo y Economía, vol. 3, n. ${ }^{\circ}$ 2, 2016, pp. 33-54. DoI: https://doi. org/10.21789/24222704.1128.

Rodríguez Salazar, Oscar. "La caja real de Popayán 1738-1800”. Anuario Colombiano de Historia Social y de la Cultura, n. ${ }^{\circ}$ I5, 1987, pp. 5-36.

TePaske, John Jay, Herbert Sanford Klein y Kendall W. Brown. Peru. Duke: Duke University Press, 1982.

TePaske, John Jay y Herbert S. Klein, eds. Upper Peru (Bolivia). Duke: Duke University Press, 1982. 